
\title{
3 Research Square \\ Spinal manipulative therapy and acupuncture for chronic low back pain: a systematic review and meta-analysis of RCTs
}

\section{Ting Yue}

The Fifth Clinical Medical School, Guangzhou University of Chinese Medicine, No.12 Jichang Road, Guangzhou, 510405, Guangdong

\section{Jingjing Li}

The First Clinical Medical School, Guangzhou University of Chinese Medicine, No.12 Jichang Road, District Baiyun, Guangzhou, 510405, Guangdong

\section{Jiaman Yang}

The Fifth Clinical Medical School, Guangzhou University of Chinese Medicine, No.12 Jichang Road, Guangzhou, 510405, Guangdong

\section{Dehui Fan ( $\nabla$ dehui_fan@163.com )}

Department of Acupuncture and rehabilitation, GuangDong Second Traditional Chinese Medicine Hospital, No.60 Hengfu Road, Guangzhou, 510405, Guangdong

\section{Research Article}

Keywords: spinal manipulation therapy, acupuncture, low back pain, complementary medicine

Posted Date: December 23rd, 2021

DOI: https://doi.org/10.21203/rs.3.rs-1192409/v1

License: (c) (i) This work is licensed under a Creative Commons Attribution 4.0 International License. Read Full License 


\section{Abstract \\ Background}

Spinal manipulation therapy (SMT) and acupuncture are commonly used for low back pain (LBP) among complementary and alternative therapies. However, it remains unclear which of the two therapies is more effective for LBP. Therefore, the purpose of this meta-analysis was to evaluate the effectiveness of SMT and acupuncture on LBP.

\section{Methods}

Four electronic databases were searched for randomized controlled trials (all years until July 2021), including PubMed, Embase, Web of Science, and Cochrane Library. Two reviewers independently abstracted data, assessed risk of bias, and rated the quality of evidence. The primary outcome was pain; secondary outcomes included functional status and adverse events. Review Manager 5.3 software and Stata 12.0 were used for all statistical analyses.

\section{Results}

9 RCTs with a total of 714 participants were identified, who were on average middle aged (39-60 years) without signs of radiating pain. These trials included patients with mild to moderate pain. Overall, moderate quality of evidence suggested that SMT had better effects for pain relief (MD: $0.32,95 \% \mathrm{Cl}: 0.09$ to $0.55, \mathrm{I}^{2}=34 \%$ ) and similar effects in function (MD: $0.24,95 \% \mathrm{Cl}:-0.45$ to $0.94, \mathrm{I}^{2}=21 \%$ ) when compared to acupuncture. Moderate quality of evidence showed SMT reduced pain better than acupuncture at month 2 (MD: $0.61,95 \% \mathrm{Cl}: 0.08$ to $1.14, \mathrm{I}^{2}=0 \%$ ) and at month 12 (MD: $1.02,95 \% \mathrm{Cl}: 0.28$ to $1.75, \mathrm{I}^{2}=42 \%$ ). In addition, Low quality of evidence showed SMT may provide better improvement in pain at month 3 (MD: $0.74,95 \% \mathrm{Cl}: 0.09$ to $1.39, \mathrm{I}^{2}=42 \%$ ) and in function at month 4 (MD: $3.50,95 \% \mathrm{Cl}: 0.71$ to 6.29 ). Adverse events associated with SMT and acupuncture were rare and mild.

\section{Conclusions}

SMT showed better effects than acupuncture for chronic low back pain, while SMT and acupuncture had similar effects in functional improvement. Although SMT and acupuncture were tolerable and safe, patients should be informed about the potential risks of adverse events before starting therapy.

\section{Introduction}

Low back pain (LBP) is the leading cause of disability in both developed and developing countries, imposing enormous health and economic burdens on society[1,2]. Not only physiological pain but also 
some psychological pressure, such as depression and anxiety, were caused by LBP[3,4]. The current clinical options include non-steroidal anti-inflammatory drugs (NSAIDs), opioid drug, oral glucocorticoids and surgery[5-7]. However, drug therapy has obvious side effects and adverse reactions[6, 8]. Surgery is not necessary because of favorable natural history of LBP[9, 10]. Therefore, non-pharmacological therapies for LBP are becoming the preferred choices[11-13].

Non-pharmacological therapies for LBP include spinal manipulation therapy (SMT), acupuncture, exercise therapy, massage, yoga, cognitive behavioral therapy, and intensive interdisciplinary treatment[3, $9,10]$. Among complementary and alternative (CAM) therapies, spinal manipulation therapy (SMT) and acupuncture are commonly used for LBP[14-16]. In some countries, SMT and acupuncture are recommended in international clinical guidelines and as first-line treatments[10,17]. Some studies comparing the effect of SMT and acupuncture on pain relief and functional improvement showed that SMT was more effective while others had opposite results[18-20]. As we know, choosing an effective and safe treatment could avoid wasting time and effort. However, although SMT and acupuncture are widely used, which type of treatment is most effective remains unclear.

In order to resolve this issue, we conducted a systematic review and meta-analysis. The primary outcome was to assess the effectiveness of SMT on pain relief when compared to acupuncture for adults with LBP. Secondary outcomes were to assess functional improvement and adverse events.

\section{Methods}

This review was performed in strict accordance with the Preferred Reporting Items for Systematic Reviews and Meta Analyses (PRISMA) guidelines[21]. Additionally, the protocol for this study was registered with PROSPERO (registration number: CRD42021256789).

\section{Searching strategies}

We searched the following electronic databases for randomized controlled trials: PubMed, Embase, Web of Science, and Cochrane Library (all years until July 2021). An experienced information specialist was consulted to help develop the search strategy according to recommendations in the Cochrane Handbook of Systematic Reviews[22]. The search strategies databases are shown in Additional file 1.

\section{Criteria for including studies for this review}

Only RCT studies were included. Studies without randomization had to be excluded. Gray literature was excluded. Studies were considered eligible for inclusion if they were of a prospective design, included adults (age $\geq 18$ years) and more than $50 \%$ of the subjects had pain for more than 3 months. In addition, the treatment group was SMT and the other group was acupuncture. In this review, we excluded studies of pelvic pain due to pregnancy, pain unrelated to the lower back, postpartum low back pain, sciatica, postoperative studies, participants with severe pathology, and studies related to maintenance or preventive therapy. 


\section{Outcome measures}

The primary outcome was pain intensity, as measured using a Visual Analogue Scale (VAS; 0-10) or Numerical Rating Pain Scale (NRS; 0-10). The secondary outcomes included functional disability and adverse events. Functional disability was assessed using Disability Index questionnaires (higher scores indicating greater disability). Adverse events were summarized descriptively.

\section{Data extraction and Risk of bias assessment}

The data were extracted from each study with a standardized form and the data integrity was crossevaluated by two researchers. In case of disagreement, a decision was made through discussion or by a third researcher (Fan) if necessary. Data extraction included the following information: design type (RCT), the authors of studies, year of publication, demographic characteristics of the intervention and control group, outcome data, follow-up intervals, adverse events, and other data, such as declaration of interests, risk of bias. The authors were contacted when necessary. The risk of bias in the included RCTs was assessed using the Cochrane Risk of Bias Tool, including selection bias, performance bias, detection bias, attrition bias, and reporting bias. These criteria were classified risk of bias as high, moderate, low and unclear[22].

\section{Data analysis}

Review Manager 5.3 software (Cochrane Collaboration) and Stata 12.0 (Stata Corp) were used for all statistical analyses. The mean difference (MD) and 95\% confidence intervals $(\mathrm{Cl})$ was used for pain and functional status. Dichotomous data were analyzed by calculating the pooled risk ratio (RR). Statistical heterogeneity was examined by a chi-square test (Cochran's $Q$ test) and $I^{2}$ test[23], and $P<0.1$ was used to indicate the presence of heterogeneity. In each case, if $P<0.1$ and $\mathrm{I}^{2} \geq 50 \%$, the more conservative random-effects models was used[24]. If $P>0.1$ and $I^{2}<50 \%$, a fixed-effects model was used.[25]. The source of heterogeneity between studies was assessed using subgroup analysis. Sensitivity analysis was subsequently performed to assess the stability of results. Funnel plot was used to assess publication bias.

\section{Results}

\section{Literature search}

Four thousand four hundred and nine records were identified from four databases. After the literature search, 3,368 duplicates were excluded. 803 records were excluded due to the title or abstract were not eligible. In the remaining 238 records, 229 studies were excluded for the

following reasons: animal researches, no data available, no back pain, no comparison, inappropriate comparison, reviews. As a result, a total of 9 RCTs were included with 714 patients in this meta- 
analysis[18-20, 26-31]. The detailed process of studies identification and screening was provided in Fig. 1.

\section{Characteristics of the included studies}

The general information of the included studies is shown in Table 1. In the included studies, the majority of patients were middle-aged patients without signs of radiating pain, typically averaging 39 to 60 years of age. Although less than half of studies described evaluation of symptom severity, most of patients reported mild to moderate pain among these studies. All of the eligible patients in the included studies had more than 6 weeks of low back pain and were performed by experienced operators using optimal technique. Moreover, none of the studies clearly distinguish between persistent low back pain and exacerbation of a chronic condition.

\section{Risk of bias in individual trial}

More than half of the studies $(55.6 \%(n=5 / 9))$ used both a random sequence generation and an allocation concealment[20, 26-28, 31]. None of the studies attempted to blind patients. Less than half of the studies $(44.4 \%(n=4 / 9))$ attempted to blind outcome assessors[18, 26, 28, 29]. More than half of the studies $(66.7 \%(n=6 / 9))$ provided an adequate follow-up and kept loss to follow-up to a minimum[18, 26$28,30,31]$. The risk of bias assessments of included studies is summarized in Fig. 2, 3.

\section{Analysis of overall effects}

Table 2 summarizes the therapeutic effects of all included studies.

\section{Primary outcomes (Pain relief):}

Eight studies compared the pain relief of SMT with acupuncture at different time points[18-20, 26-29, 31]. Overall, moderate quality of evidence suggested that SMT may reduce pain compared with acupuncture. More than half studies $(n=6 / 9)$ with high to moderate quality of evidence achieved a "moderate" assessment. Likewise, moderate quality of evidence showed SMT may reduce pain better than acupuncture at month 2 and 12, and the same result was showed at month 3 based on low quality of evidence (Fig 4.). Sensitivity analyses and random-effects models were conducted, while the results remained similar.

\section{Secondary outcomes (functional status):}

Eight studies compared the functional status of SMT with acupuncture at different time points[18-20, 2630]. Overall, Moderate quality evidence suggested that there was no statistical difference between SMT and acupuncture, while low quality of evidence showed that SMT may provide better effects compared with acupuncture at month 4(Fig 5.). Sensitivity analyses and random-effects models were conducted, while the results remained unchanged. Funnel plots showed no evidence of publication bias (Fig 6.)

\section{Adverse events:}


Less half of the studies (33.3\% ( $n=3 / 9)$ ) examined adverse events (table 3). However, one of these studies examined the incidence of these events[27]. That study $(n=172)$ suggested $13 \%$ of patients in the SMT group and $11 \%$ in the acupuncture group reported significant pain or discomfort during or shortly after treatment. There was no serious adverse event described in the included studies.

\section{Discussion}

Spinal manipulation therapy (SMT) and acupuncture are commonly used for the treatment of LBP and recommended as first-line treatments in most countries[10,17]. However, it's not clear which of the two therapies is more effective. This meta-analysis included 9 RCTs with 714 patients to evaluate the efficacy and safety of SMT and acupuncture for LBP. Based on moderate quality evidence, overall analysis suggested that SMT may reduce pain compared with acupuncture, while there was no statistical difference between SMT and acupuncture for improving function. Moderate quality of evidence showed SMT may reduce pain better than acupuncture at month 2 and 12, and the same result was showed at month 3 based on low quality of evidence. Low quality of evidence showed SMT may provide better functional improvements compared with acupuncture at month 4 . Sensitivity analyses and randomeffects models did not significantly change the results. Finally, there was no serious adverse event described in the included studies.

SMT and acupuncture was prevalently used among patients with chronic LBP[32-34]. Among CAM treatments for low back pain, receptivity was highest for acupuncture and SMT therapies by physician and patients[34,35]. Most studies validated effects of SMT and acupuncture in clinical trials and therefore this might increase the reliability of the outcomes[14, 15,36]. Evidence quality of included studies was limited by low-to-moderate quality, suggesting some uncertainty surrounding research results. However, these results were similar in sensitivity analyses and random-effects models. In addition, we further performed subgroup analyses by number of patients and publication time. There was small significant difference in the subgroup of patients with less than this number $(n \leq 35)$, indicating SMT may reduce pain better than acupuncture, while the remaining results were not statistically significant differences. The result may be inaccurate and have possible bias due to the small sample sizes. Furthermore, our results are largely consistent with other published high-quality reviews [37, 38].

\section{Limitations of this study}

Although we conducted a comprehensive review of the literature on using SMT and acupuncture to treat patients with LBP, there are some limitations. The main limitations are similar to most systematic reviews -namely, the variable quality and data integrity of included studies, as well as ambiguity about the impact of publication bias. Furthermore, we were unable to resolve the problem related to statistical heterogeneity, and this reduced the reliability of the evidences in our meta-analysis. Finally, most studies were conducted in the United States and Australia, and a few studies in China and other countries due to various reasons were excluded, which may cause potentiality for bias. 


\section{Conclusions}

Overall, SMT produces a better effect for chronic low back pain in pain reduction compared with acupuncture, especially at the medium and long-term follow up. For back specific functional status, SMT may provide better medium-term effects compared with acupuncture. Adverse events associated with SMT and acupuncture were rare and mild, and there were no severe adverse events.

\section{References}

1. Hoy D, March L, Brooks P, Blyth F, Woolf A, Bain C, Williams G, Smith E, Vos T, Barendregt J et al: The global burden of low back pain: estimates from the Global Burden of Disease 2010 study. Annals of the rheumatic diseases 2014, 73(6):968-974.

2. Global, regional, and national incidence, prevalence, and years lived with disability for $\mathbf{3 0 1}$ acute and chronic diseases and injuries in 188 countries, 1990-2013: a systematic analysis for the Global Burden of Disease Study 2013. Lancet (London, England) 2015, 386(9995):743-800.

3. Saper RB, Lemaster C, Delitto A, Sherman KJ, Herman PM, Sadikova E, Stevans J, Keosaian JE, Cerrada CJ, Femia AL et al: Yoga, Physical Therapy, or Education for Chronic Low Back Pain: A Randomized Noninferiority Trial. Annals of internal medicine 2017, 167(2):85-94.

4. Pinto RZ, Maher CG, Ferreira ML, Ferreira PH, Hancock M, Oliveira VC, McLachlan AJ, Koes B: Drugs for relief of pain in patients with sciatica: systematic review and meta-analysis. BMJ (Clinical research ed) 2012, 344:e497.

5. Balagué F, Mannion AF, Pellisé F, Cedraschi C: Non-specific low back pain. Lancet (London, England) 2012, 379(9814):482-491.

6. Morone NE, Greco CM, Moore CG, Rollman BL, Lane B, Morrow LA, Glynn NW, Weiner DK: A MindBody Program for Older Adults With Chronic Low Back Pain: A Randomized Clinical Trial. JAMA internal medicine 2016, 176(3):329-337.

7. Maher C, Underwood M, Buchbinder R: Non-specific low back pain. Lancet (London, England) 2017, 389(10070):736-747.

8. Bertsche T, Mikus G: [Adverse drug reactions and drug interactions in analgesic therapy]. Therapeutische Umschau Revue therapeutique 2011, 68(1):19-26.

9. Chou R, Deyo R, Friedly J, Skelly A, Hashimoto R, Weimer M, Fu R, Dana T, Kraegel P, Griffin J et al: Nonpharmacologic Therapies for Low Back Pain: A Systematic Review for an American College of Physicians Clinical Practice Guideline. Annals of internal medicine 2017, 166(7):493-505.

10. Qaseem A, Wilt TJ, McLean RM, Forciea MA, Denberg TD, Barry MJ, Boyd C, Chow RD, Fitterman N, Harris RP et al: Noninvasive Treatments for Acute, Subacute, and Chronic Low Back Pain: A Clinical Practice Guideline From the American College of Physicians. Annals of internal medicine 2017, 166(7):514-530.

11. Dubois J, Scala E, Faouzi M, Decosterd I, Burnand B, Rodondi PY: Chronic low back pain patients' use of, level of knowledge of and perceived benefits of complementary medicine: a cross-sectional study 
at an academic pain center. BMC complementary and alternative medicine 2017, 17(1):193.

12. Schafer LM, Hsu C, Eaves ER, Ritenbaugh C, Turner J, Cherkin DC, Sims C, Sherman KJ: Complementary and alternative medicine (CAM) providers' views of chronic low back pain patients' expectations of CAM therapies: a qualitative study. BMC complementary and alternative medicine 2012, 12:234.

13. Liu L, Tang Y, Baxter GD, Yin H, Tumilty S: Complementary and alternative medicine - practice, attitudes, and knowledge among healthcare professionals in New Zealand: an integrative review. BMC complementary medicine and therapies 2021, 21(1):63.

14. Berman BM, Langevin HM, Witt CM, Dubner R: Acupuncture for chronic low back pain. The New England journal of medicine 2010, 363(5):454-461.

15. Paige NM, Miake-Lye IM, Booth MS, Beroes JM, Mardian AS, Dougherty P, Branson R, Tang B, Morton SC, Shekelle PG: Association of Spinal Manipulative Therapy With Clinical Benefit and Harm for Acute Low Back Pain: Systematic Review and Meta-analysis. Jama 2017, 317(14):1451-1460.

16. Manyanga T, Froese M, Zarychanski R, Abou-Setta A, Friesen C, Tennenhouse M, Shay BL: Pain management with acupuncture in osteoarthritis: a systematic review and meta-analysis. $B M C$ complementary and alternative medicine 2014, 14:312.

17. Delitto A, George SZ, Van Dillen L, Whitman JM, Sowa G, Shekelle P, Denninger TR, Godges JJ: Low back pain. The Journal of orthopaedic and sports physical therapy 2012, 42(4):A1-57.

18. Griswold D, Gargano F, Learman KE: A randomized clinical trial comparing non-thrust manipulation with segmental and distal dry needling on pain, disability, and rate of recovery for patients with nonspecific low back pain. The Journal of manual \& manipulative therapy 2019, 27(3):141-151.

19. Kizhakkeveettil A, Rose KA, Kadar GE, Hurwitz EL: An Exploratory Analysis of Gender as a Potential Modifier of Treatment Effect Among Patients in a Randomized Controlled Trial of Integrative Acupuncture and Spinal Manipulation for Low Back Pain. Journal of manipulative and physiological therapeutics 2019, 42(3):177-186.

20. Kizhakkeveettil A, Rose KA, Kadar GE, Hurwitz EL: Integrative Acupuncture and Spinal Manipulative Therapy Versus Either Alone for Low Back Pain: A Randomized Controlled Trial Feasibility Study. Journal of manipulative and physiological therapeutics 2017, 40(3):201-213.

21. Moher D, Liberati A, Tetzlaff J, Altman DG, Group P: Preferred reporting items for systematic reviews and meta-analyses: the PRISMA statement. BMJ (Clinical research ed) 2009, 339:b2535.

22. Cumpston M, Li T, Page MJ, Chandler J, Welch VA, Higgins JP, Thomas J: Updated guidance for trusted systematic reviews: a new edition of the Cochrane Handbook for Systematic Reviews of Interventions. The Cochrane database of systematic reviews 2019, 10:Ed000142.

23. Higgins JP, Thompson SG, Deeks JJ, Altman DG: Measuring inconsistency in meta-analyses. BMJ (Clinical research ed) 2003, 327(7414):557-560.

24. DerSimonian R, Laird N: Meta-analysis in clinical trials. Controlled clinical trials 1986, 7(3):177-188.

25. Moher D, Liberati A, Tetzlaff J, Altman DG: Preferred reporting items for systematic reviews and meta-analyses: the PRISMA statement. BMJ (Clinical research ed) 2009, 339:b2535. 
26. Giles LG, Müller R: Chronic spinal pain syndromes: a clinical pilot trial comparing acupuncture, a nonsteroidal anti-inflammatory drug, and spinal manipulation. Journal of manipulative and physiological therapeutics 1999, 22(6):376-381.

27. Cherkin DC, Eisenberg D, Sherman KJ, Barlow W, Kaptchuk TJ, Street J, Deyo RA: Randomized trial comparing traditional Chinese medical acupuncture, therapeutic massage, and self-care education for chronic low back pain. Archives of internal medicine 2001, 161(8):1081-1088.

28. Giles LG, Muller R: Chronic spinal pain: a randomized clinical trial comparing medication, acupuncture, and spinal manipulation. Spine 2003, 28(14):1490-1502; discussion 1502-1493.

29. Muller R, Giles LG: Long-term follow-up of a randomized clinical trial assessing the efficacy of medication, acupuncture, and spinal manipulation for chronic mechanical spinal pain syndromes. Journal of manipulative and physiological therapeutics 2005, 28(1):3-11.

30. Klassen E, Wiebelitz KR, Beer AM: Classical Massage and Acupuncture in Chronic Back Pain - NonInferiority Randomised Trial. Zeitschrift fur Orthopadie und Unfallchirurgie 2019, 157(3):263-269.

31. Kalauokalani D, Cherkin DC, Sherman KJ, Koepsell TD, Deyo RA: Lessons from a trial of acupuncture and massage for low back pain: patient expectations and treatment effects. Spine 2001, 26(13):1418-1424.

32. Elder C, DeBar L, Ritenbaugh C, Vollmer W, Deyo RA, Dickerson J, Kindler L: Acupuncture and chiropractic care: utilization and electronic medical record capture. The American journal of managed care 2015, 21(7):e414-421.

33. Ng JY, Mohiuddin U: Quality of complementary and alternative medicine recommendations in low back pain guidelines: a systematic review. European spine journal: official publication of the European Spine Society, the European Spinal Deformity Society, and the European Section of the Cervical Spine Research Society 2020, 29(8):1833-1844.

34. Ng JY, Anagal M, Bhowmik T: Low back pain patients' perceived effectiveness of utilizing complementary and alternative medicine: a systematic review of qualitative studies. Journal of complementary \& integrative medicine 2021.

35. DeBar LL, Elder C, Ritenbaugh C, Aickin M, Deyo R, Meenan R, Dickerson J, Webster JA, Jo Yarborough B: Acupuncture and chiropractic care for chronic pain in an integrated health plan: a mixed methods study. BMC complementary and alternative medicine 2011, 11:118.

36. Xue CC, Zhang AL, Lin V, Myers R, Polus B, Story DF: Acupuncture, chiropractic and osteopathy use in Australia: a national population survey. BMC public health 2008, 8:105.

37. Rubinstein SM, de Zoete A, van Middelkoop M, Assendelft WJJ, de Boer MR, van Tulder MW: Benefits and harms of spinal manipulative therapy for the treatment of chronic low back pain: systematic review and meta-analysis of randomised controlled trials. BMJ (Clinical research ed) 2019, 364:1689.

38. Chou R, Deyo R, Friedly J, Skelly A, Hashimoto R, Weimer M, Fu R, Dana T, Kraegel P, Griffin J et al: AHRQ Comparative Effectiveness Reviews. In: Noninvasive Treatments for Low Back Pain. edn. Rockville (MD): Agency for Healthcare Research and Quality (US); 2016. 


\section{Tables}

Table 1. Summary of clinical and treatment characteristics for all included studies

\begin{tabular}{|c|c|c|c|c|c|c|}
\hline Author & $\begin{array}{l}\text { Study } \\
\text { type }\end{array}$ & $\begin{array}{l}\text { Radiating } \\
\text { pain }\end{array}$ & $\begin{array}{l}\text { Duration of } \\
\text { LBP }\end{array}$ & $\begin{array}{l}\text { Duration of } \\
\text { treatment }\end{array}$ & Treatments & $\begin{array}{l}\text { Quality of } \\
\text { the study }\end{array}$ \\
\hline $\begin{array}{l}\text { Anupama } \\
2017\end{array}$ & $\mathrm{RCT}$ & no & Imprecision & 2 months & SMT vs AC & low \\
\hline Cherkin 2001 & $\mathrm{RCT}$ & no & $>6$ weeks & 2 months & SMT vs AC & moderate \\
\hline $\begin{array}{l}\text { Griswolda } \\
2019\end{array}$ & RCT & no & $>6$ weeks & 1 month & SMT vs AC & high \\
\hline $\begin{array}{l}\text { Kalauokalani } \\
2001\end{array}$ & $\mathrm{RCT}$ & no & $>6$ weeks & 2 months & SMT vs AC & moderate \\
\hline $\begin{array}{l}\text { Kizhakkeveettil } \\
2019\end{array}$ & $\mathrm{RCT}$ & no & $>6$ weeks & 2 months & SMT vs AC & low \\
\hline Klassen 2019 & $\mathrm{RCT}$ & no & Imprecision & 2 weeks & SMT vs AC & moderate \\
\hline Lynton 1999 & RCT & no & $>13$ weeks & 1 month & SMT vs AC & moderate \\
\hline Lynton 2003 & RCT & no & $>13$ weeks & 2 months & SMT vs AC & moderate \\
\hline Muller 2005 & RCT & no & $>13$ weeks & 2 months & SMT vs AC & moderate \\
\hline
\end{tabular}

Footnotes: SMT = spinal manipulative therapy; $\mathrm{AC}=$ acupuncture;

Table 2. Summary of therapeutic effects and GRADE assessment for all included studies 
Quality of evidence

\begin{tabular}{|c|c|c|c|c|c|}
\hline Analyses & $\begin{array}{l}\text { Effect estimate } \\
(95 \% \mathrm{Cl})\end{array}$ & studies & participants & $\mathrm{I}^{2}(\%)$ & (reason for downgrading) \\
\hline \multicolumn{6}{|c|}{ SMT versus Acupuncture } \\
\hline \multicolumn{6}{|l|}{ Pain: } \\
\hline 2 week & $-1.61(-3.86$ to 0.65$)$ & 3 & 199 & 49 & Moderate (inconsistency) \\
\hline 1 month & $-0.16(-0.56$ to 0.24$)$ & 5 & 482 & 31 & Moderate (inconsistency) \\
\hline 2 month & $0.61(0.08$ to 1.14$)$ & 4 & 339 & 0 & Moderate (limitations) \\
\hline 3 month & $0.74(0.09$ to 1.39$)$ & 2 & 241 & 42 & Low (limitations, imprecision) \\
\hline 4 month & $0.90(-0.18$ to 1.98$)$ & 1 & 69 & - & Low (limitations, imprecision) \\
\hline 12 month & $1.02(0.28$ to 1.75$)$ & 3 & 248 & 42 & Moderate (inconsistency) \\
\hline Total & $0.32(0.09$ to 0.55$)$ & 18 & 1578 & 34 & Moderate (limitations) \\
\hline \multicolumn{6}{|l|}{ Function: } \\
\hline 2 week & $-2.75(-6.61$ to 1.12$)$ & 3 & 199 & 49 & Moderate (inconsistency) \\
\hline 1 month & $0.41(-2.18$ to 2.99$)$ & 4 & 354 & 55 & Moderate (inconsistency) \\
\hline 2 month & $0.14(-0.90$ to 1.17$)$ & 5 & 476 & 0 & Moderate (limitations) \\
\hline 3 month & $0.36(-0.81$ to 1.52$)$ & 3 & 378 & 0 & Low (limitations, imprecision) \\
\hline 4 month & $3.50(0.71,6.29)$ & 1 & 69 & - & Low (limitations, imprecision) \\
\hline 12 month & $0.12(-1.53,1.76)$ & 3 & 248 & 0 & Moderate (inconsistency) \\
\hline Total & $0.24(-0.45,0.94)$ & 19 & 1724 & 21 & Moderate (limitations) \\
\hline
\end{tabular}

Table 3. Summary of adverse event reporting for all included studies 


\begin{tabular}{llll}
$\begin{array}{l}\text { Study, sample } \\
\text { size }\end{array}$ & $\begin{array}{l}\text { Methods used to assess } \\
\text { adverse events }\end{array}$ & $\begin{array}{l}\text { Adverse } \\
\text { events } \\
\text { reporting }\end{array}$ & $\begin{array}{l}\text { Adverse events reported (for SMT } \\
\text { or control group) }\end{array}$ \\
$\begin{array}{l}\text { Lynton 1999, } \\
\mathrm{n}=48\end{array}$ & Not reported & $\begin{array}{l}\text { Any adverse } \\
\text { event }\end{array}$ & No adverse events reported \\
\hline $\begin{array}{l}\text { Cherkin 2001, } \\
\mathrm{n}=172\end{array}$ & $\begin{array}{l}\text { Self-reported during } \\
\text { treatment and follow-up }\end{array}$ & $\begin{array}{l}\text { Any adverse } \\
\text { event }\end{array}$ & $\begin{array}{l}\text { No serious adverse effects were } \\
\text { reported by any patients. }\end{array}$ \\
\hline $\begin{array}{l}\text { Lynton 2003, } \\
\mathrm{n}=47\end{array}$ & $\begin{array}{l}\text { Self-reported during } \\
\text { treatment and follow-up }\end{array}$ & $\begin{array}{l}\text { Any adverse } \\
\text { event }\end{array}$ & No adverse events reported \\
\hline $\begin{array}{l}\text { Muller 2005, } \\
\mathrm{n}=43\end{array}$ & Not reported & $\begin{array}{l}\text { Any adverse } \\
\text { event }\end{array}$ & No adverse events reported \\
\hline $\begin{array}{l}\text { Anupama } \\
2017, \mathrm{n}=69\end{array}$ & $\begin{array}{l}\text { Self-reported during } \\
\text { treatment and follow-up }\end{array}$ & $\begin{array}{l}\text { Any adverse } \\
\text { event }\end{array}$ & No adverse events reported \\
\hline $\begin{array}{l}\text { Kizhakkeveettil } \\
2019, \mathrm{n}=51\end{array}$ & Not reported & $\begin{array}{l}\text { Any adverse } \\
\text { event }\end{array}$ & No adverse events reported \\
\hline $\begin{array}{l}\text { Griswolda } \\
2019, \mathrm{n}=65\end{array}$ & Not reported & $\begin{array}{l}\text { Any adverse } \\
\text { event }\end{array}$ & No adverse events reported \\
\hline $\begin{array}{l}\text { Kalauokalani } \\
2001, \mathrm{n}=137\end{array}$ & Not reported & $\begin{array}{l}\text { Any adverse } \\
\text { event }\end{array}$ & No adverse events reported \\
\hline $\begin{array}{l}\text { Klassen 2019, } \\
\mathrm{n}=126\end{array}$ & Not reported & $\begin{array}{l}\text { Any adverse } \\
\text { event }\end{array}$ & No adverse events reported \\
\hline
\end{tabular}

\section{Figures}




\section{Identification of studies via databases and registers}

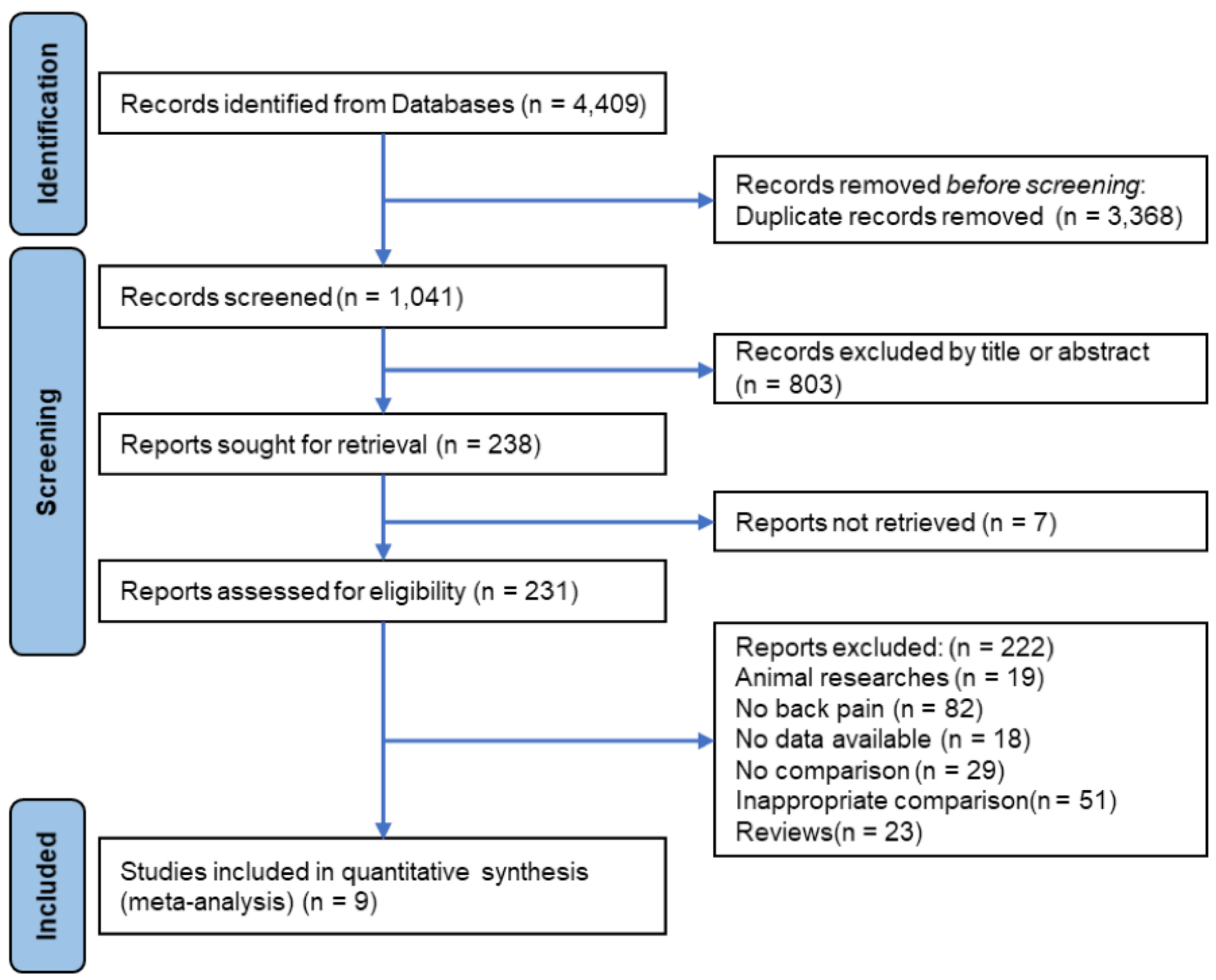

Figure 1

Selection of studies through review 


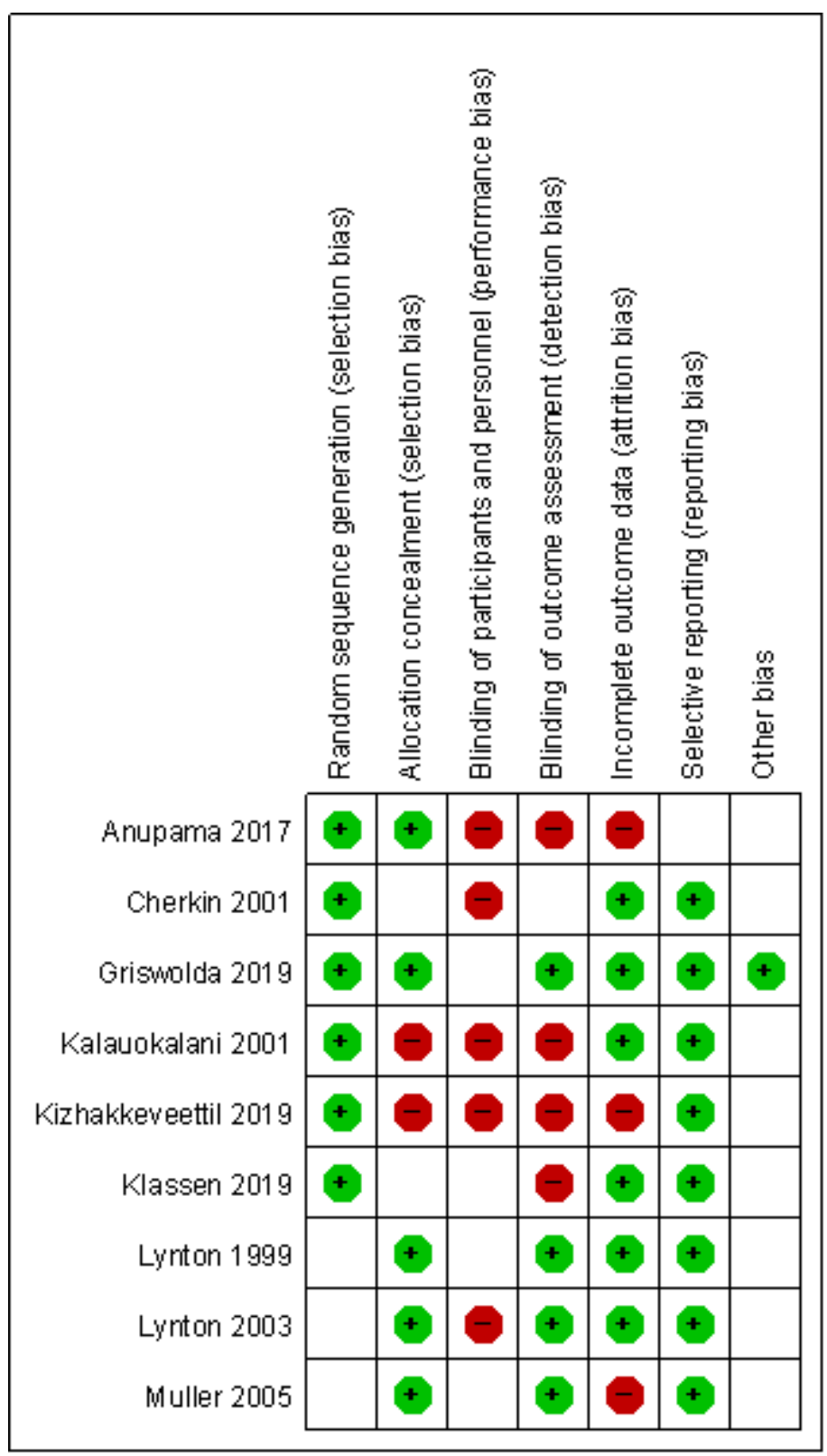

Figure 2

Risk of bias assessment using the Cochrane tool 


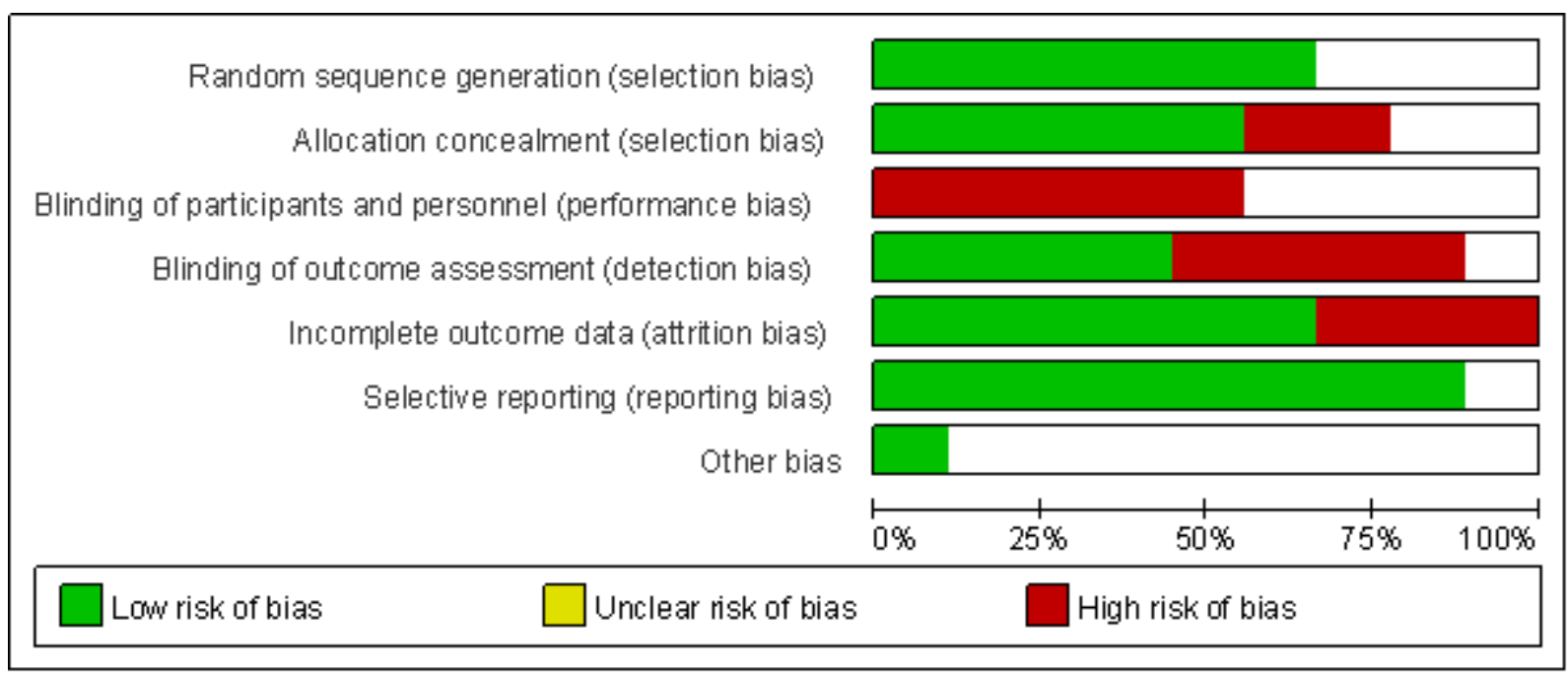

\section{Figure 3}

Risk of bias assessment using the Cochrane tool 


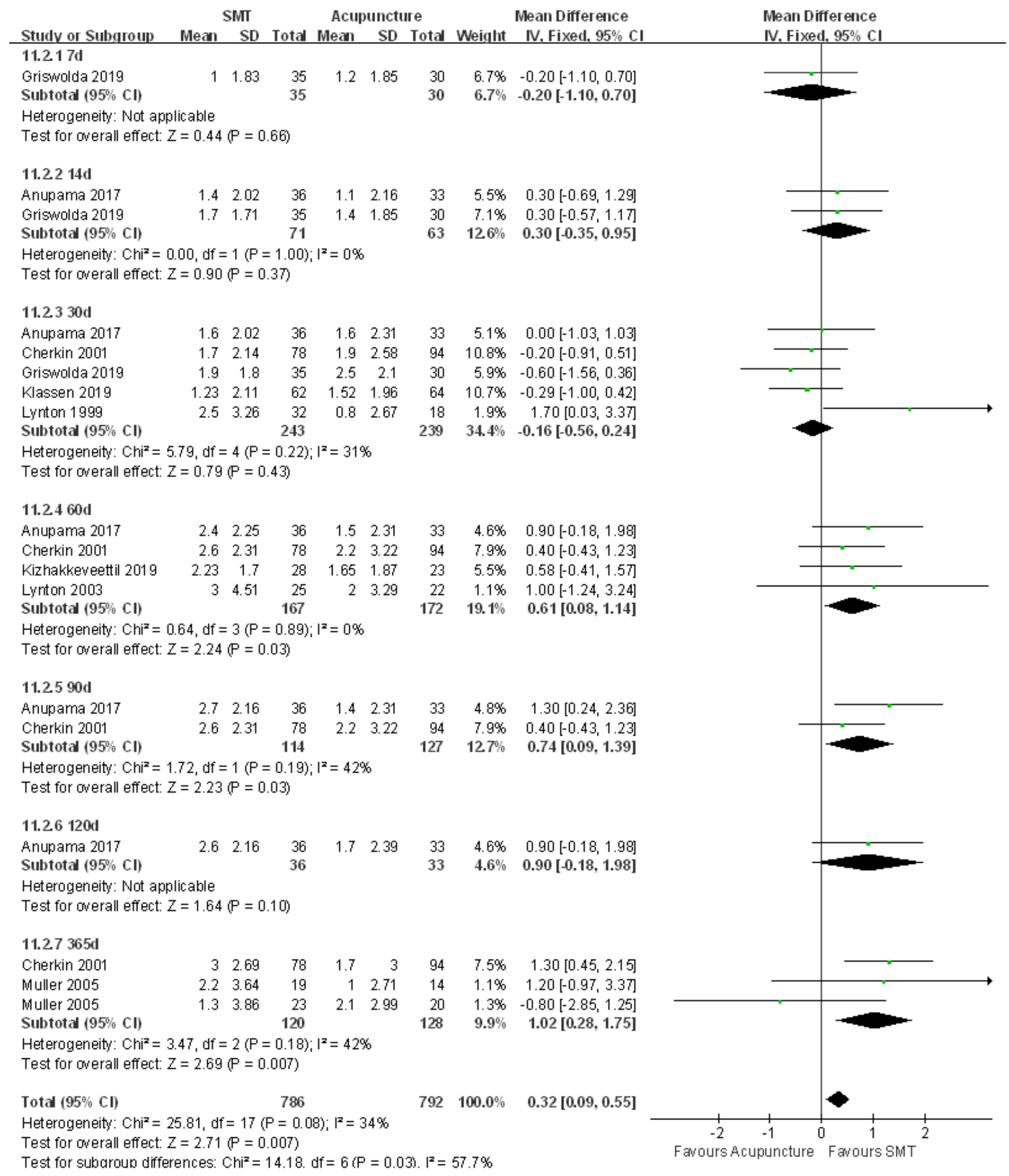

\section{Figure 4}

Forest plot: SMT vs acupuncture for pain 


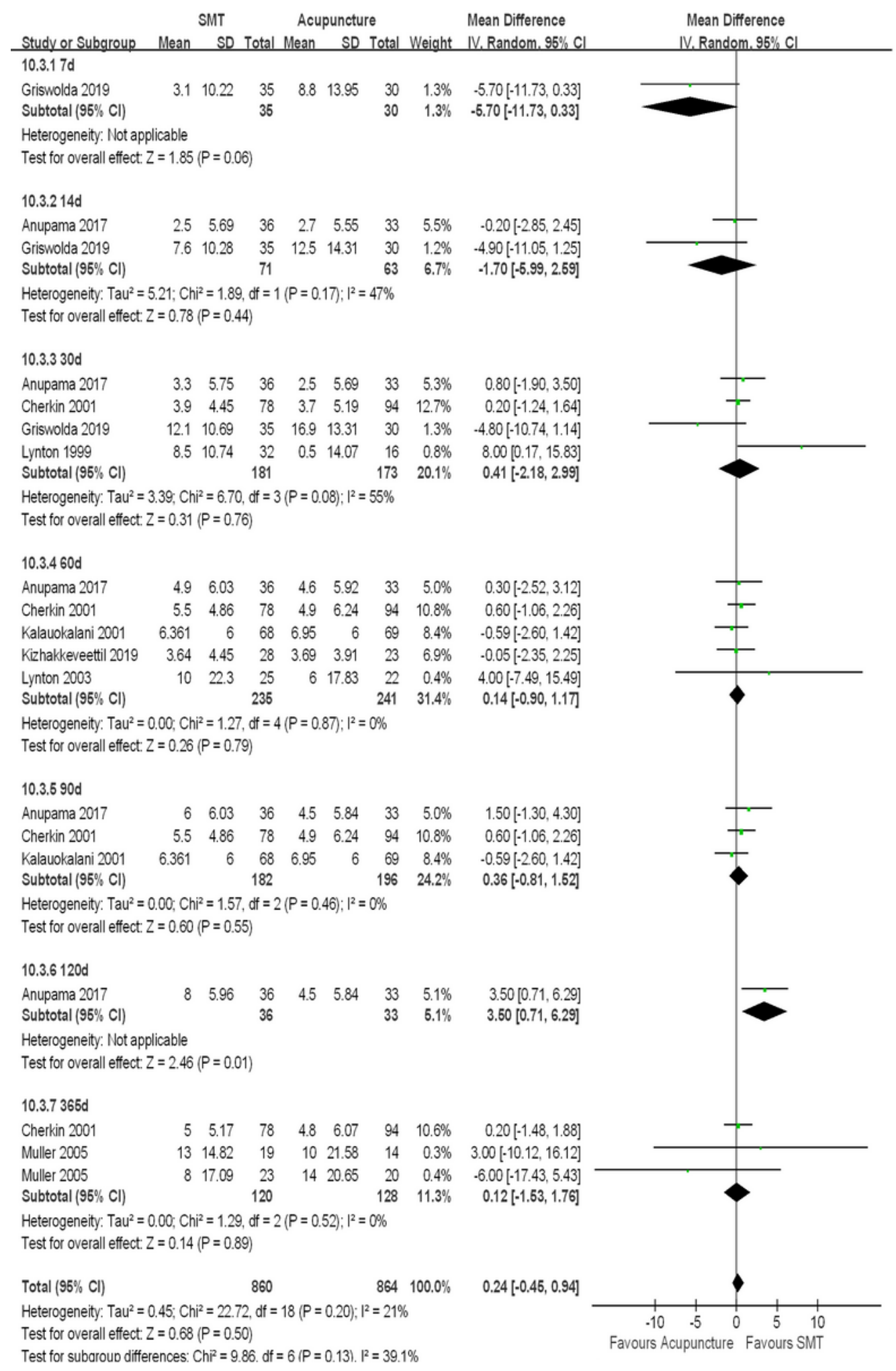

\section{Figure 5}

Forest plot: SMT vs acupuncture for functional status 
Begg's funnel plot with pseudo $95 \%$ confidence limits

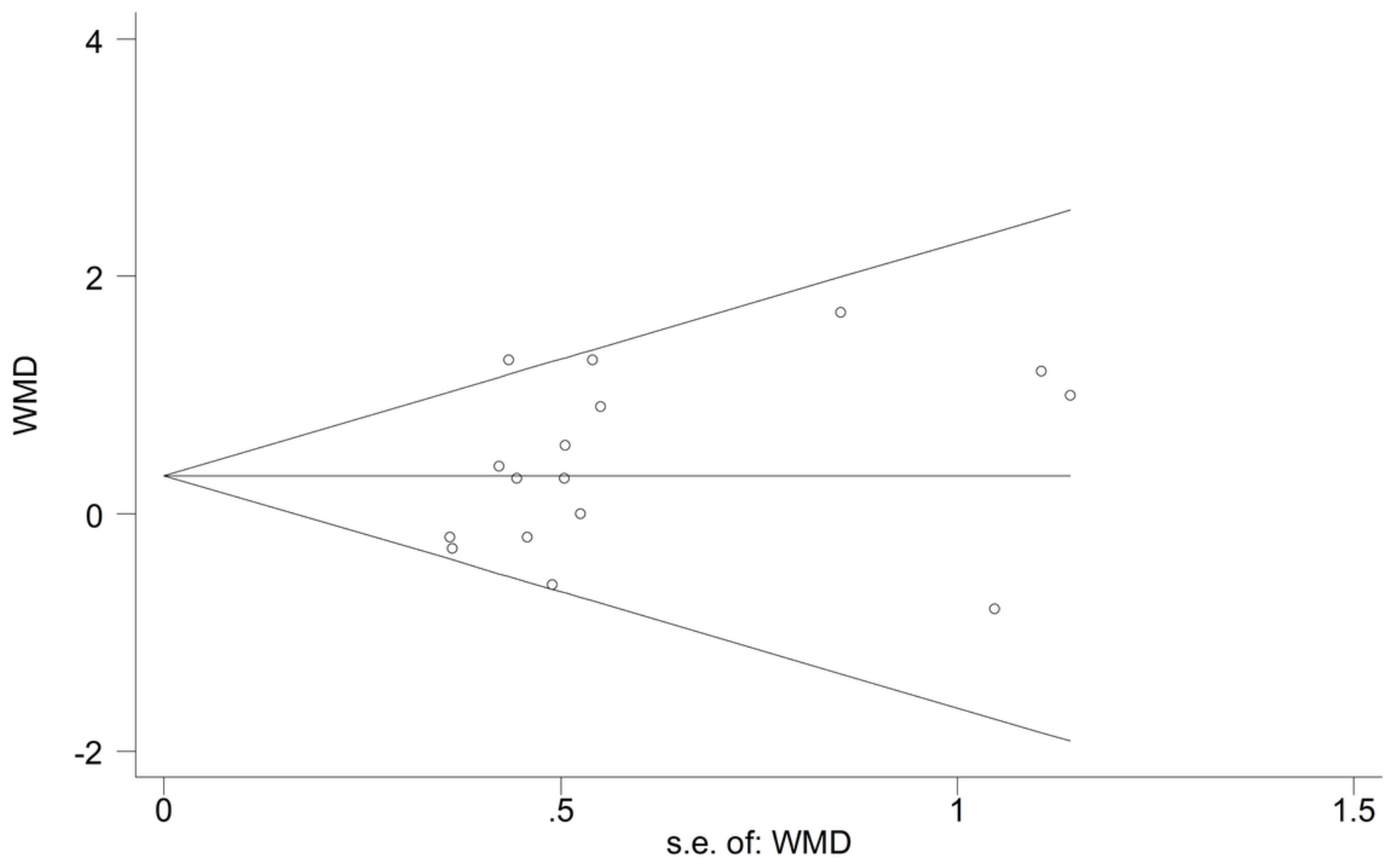

Figure 6

Funnel plots of pain and functional status.

Publication bias: $\mathrm{P}=0.162>0.05$

\section{Supplementary Files}

This is a list of supplementary files associated with this preprint. Click to download.

- Additionalfile1.docx 